A C T A C H E M I A S C A N D I N A V I C A 19 (1965) $729-734$

\title{
Stability of the Tetracyanocuprate(II) Complex from E.M.F. Measurements in a Methanol-Water Solvent at Low Temperature
}

\author{
RUSSELL PATERSON and JANNIK BJERRUM
}

\begin{abstract}
Department I, Inorganic Chemistry, The H. C. Ørsted Institute, University of Copenhagen, Copenhagen, Denmark
\end{abstract}

\begin{abstract}
An estimate of the overall stability constant of the tetracyanocuprate(II) ion, which has only a short lifetime at room temperature, has been made in aqueous methanol solution at $-45^{\circ}$ using a potentiometric method. $\log \beta_{4}$ was found to be 26.7 , and it was confirmed that the rate of decomposition of the tetracyanocuprate ion is second order in the concentration of this ion.
\end{abstract}

$T^{t}$ is well-known from the qualitative analysis that addition of cyanide to

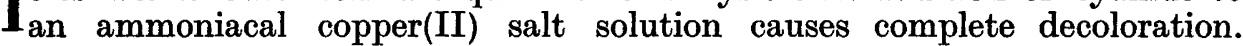
However, the momentary increase in the colour intensity before decoloration is often unnoticed. This reaction has been examined by Duke and Courtney, who postulate the existence of an intermediate tetracyanocuprate(II) complex, which undergoes a redox reaction:

$$
2 \mathrm{Cu}(\mathrm{CN})_{4}^{2-} \rightarrow 2 \mathrm{Cu}(\mathrm{CN})_{3}^{2-}+(\mathrm{CN})_{2}
$$

Baxendale and Westcott ${ }^{2}$ have later studied the reaction with cyanide $\left(\sim 10^{-3} \mathrm{M}\right)$ in aqueous solution at $\mathrm{pH} \sim 5$, and at very low copper concentration $\left(\sim 10^{-5} \mathrm{M}\right)$ and found that the rate of formation of the dicyanocuprate(I) (followed spectrophotometrically in the high absorption band at $234 \mathrm{~m} \mu$ ) is 2nd order in the copper(II) concentration and 6th order in the cyanide concentration. As the formation of the copper(II)cyanide complexes is instantaneous, and $\bar{n} \approx 1$ under the experimental conditions considered, the results of Baxendale and Westcott are consistent with the assumption that either $\mathrm{Cu}(\mathrm{CN})_{3}{ }^{-}$or $\mathrm{Cu}(\mathrm{CN})_{4}^{2-}$ reacts bimolecularly according to a redox reaction as given above.

In a personal communication from D. F. Evans to Griffith, ${ }^{3}$ Evans reported that the cupric cyanide complex exists as a stable purple complex in methanol at $-70^{\circ}$. In the present study the complexity of this complex is determined in aqueous methanol by e.m.f. measurements.

Acta Chem. Scand. 19 (1965) No. 3 
The potentials for the solvated copper(II) ion-copper and the tetracyanocuprate(I)-copper couples and the tetracyanocuprate(II)-tetracyanocuprate(I) couple were measured with a copper amalgam and a platinum electrode, respectively. The medium was chosen as $60 \mathrm{wt}$. $\%$ methanol, and a temperature of $-45^{\circ}$ was found to be sufficiently low to slow down the redox reaction. A constant salt molality of approximately 0.1 was maintained by using sodium $p$-toluenesulphonate as inert salt.

It was necessary to exclude oxygen, and a special technique was developed in order to carry out the e.m.f. measurements in a low temperature cryostat.

\section{EXPERIMENTAL}

Materials. Sodium $p$-toluenesulphonate (NaT) was prepared $99.9 \%$ pure by recrystallisation from $90 \%$ aqueous methanol, dried at $105^{\circ}$ and stored over phosphorus pentoxide.

Cupric $p$-toluenesulphonate $\left(\mathrm{CuT}_{2}\right)$ was prepared by the reaction of $p$-toluenesulphonic acid with AnalaR cupric oxide and obtained $99.9 \%$ pure and anhydrous by recrystallisa. tion from water, and air drying at $132^{\circ}$. Analysis was carried out by electrodeposition of copper.

The mercury (B.D.H.) and sodium cyanide (Baker) were of AnalaR grade. solution.

Copper amalgam was prepared in bulk by electrolysis, ${ }^{4}$ and stored under cupric nitrate

The nitrogen used was purified by passing through a Meyer-Ronge column. ${ }^{5}$

Methanol solvent. The solvent used throughout was an aqueous methanol solution of composition 0.45 mole fraction in methanol or $60 \%$ by weight made from Merck's methanol p.a.

Solutions were prepared on the molal scale per $1000 \mathrm{~g}$ solvent and analyzed by titration methods; $\mathrm{Cu}$ (II) by EDTA murexide titration ${ }^{3}$ and cyanide by Liebig's method." In each case the presence of methanol in solution was shown to have no influence.

Stock solutions of cuprous cyanide were most conveniently prepared by mixing cupric $p$-toluenesulphonate and sodium cyanide solutions under anaerobic conditions at room temperature. An intense violet coloration developed immediately, rapidly fading to give a water clear copper(I) solution. The cyanogen produced in the reduction was removed in a brisk nitrogen stream.

Apparatus. The electrode vessel consisted of a five-necked $500 \mathrm{ml}$ round bottomed flask. Each neck was fitted with a standard ground glass joint. Three of the necks had B 29 sockets and could accommodate two electrodes and a stirrer, when required. Of the two remaining necks one, fitted with a bubbler, provided an outlet for the $\mathrm{N}_{2}$-stream, which entered the vessel from the bottom by way of a $1 \mathrm{~mm}$ capillary. The other neck, which was fitted with a bored rubber disc and sealed with a rubber stopper, was used for addition of copper solutions.

Modified glass syringes with glass needles, which could be sealed with removable polythene caps, were used as weight burettes for the addition of precooled solutions.

All electrodes were constructed as immersion electrodes, mounted on B 29 standard ground glass cones. Mercury and amalgam holders were siliconised by the method of Hills and Ives, ${ }^{8}$ and the platinum/glass seals were reinforced with Araldite.

Calomel electrodes. The mercury reservoir consisted of a sma!l test-tube with two holes blown $4 \mathrm{~cm}$ from the bottom. Mercury was introduced into the tube and electrical contact made via a Pt-seal in a thin glass tube. A film of dry calomel/mercury powder was placed on the surface ${ }^{8}$ and overlaid with a $3 \mathrm{~mm}$ layer of $\mathrm{Hg}_{2} \mathrm{Cl}_{2} / \mathrm{Hg}$ paste prepared by the method of Gjaldbæk ${ }^{2}$ using the methanol solvent, $0.02 \mathrm{~m} \mathrm{NaCl}+0.08 \mathrm{~m} \mathrm{NaT}$, as electrode solution. The test tube with its contents was immersed in the electrode solution in the main electrode holder and electrical contact with test solutions made via a $0.5 \mathrm{~mm}$ capillary and a ground glass standard joint.

A pair of such electrodes were prepared and stored immersed in their electrode solution in the cryostat. 
Copper amalgam electrodes. The amalgam holder consisted of a J-tube, which contained the amalgam, with which electrical contact was made via a Pt-seal. This holder was mounted in an outer tube which terminated in a $1 \mathrm{~mm}$ outlet. A system of outlets allowed this outer jacket to be flushed with nitrogen maintaining the electrode surface dry, or by redirection of the flow to sweep over the surface of the solution in the filled electrode. In this way it was possible to allow the system to deaerate fully before readings were taken.

Platinum electrodes. These consisted of $1 \times 1 \mathrm{~cm}^{2} \mathrm{Pt}$ foil sheets sealed into glass tubing. A pair of these were mounted on a single B 29 cone.

The e.m.f. measurements were made using a Cambridge Vernier potentiometer and a Light Spot Galvanometer with adjustable magnetic shunt. The solutions were maintained at the required temperature $\pm \mathbf{0 . 0 3}^{\circ}$ in a thermostated methanol bath of a Lauda UltraKryostat, Type UK 80 DW.

Potential measurements with Pt electrode in cyanide containing solutions. The electrode vessel, fitted with $\mathrm{Pt}$ electrodes and a stirrer, was filled with a known weight of a cuprous cyanide solution prepared as already mentioned, or in some cases (where the kinetics of the redox reaction was followed) with a pure sodium cyanide solution. It was then cooled to the required temperature, and the nitrogen flow (precooled) continued until the cell reached bath temperature. The calomel electrode was transferred from its jacket in the cooled bath and fitted to the electrode vessel. The syringe which served as weight burette was filled with oxygenfree cupric $p$-toluenesulphonate and cooled to bath temperature. After complete deaeration of the system the experiments were started by injection of the cooled $\mathrm{Cu}$ (II) solution, and a series of readings of e.m.f. vs. time were taken. However, in spite of all possible care, these measurements could not be reproduced better than within two millivolts.

Potential measurements with the copper-amalgam electrode. This electrode was fitted to the electrode vessel, which was then filled with an analyzed solution of either cuprous cyanide or solvated cupric ions. The electrode solution was isolated from the amalgam by flushing nitrogen through the terminal capillary of the electrode holder, and deaerated for at least one hour also in case of the simple measurements of solutions of uncomplexed cupric ions. The e.m.f. measurements were made by redirecting the nitrogen flow and allowing the solution level in the amalgam electrode to rise by equalisation of pressures.

In the measurements with uncomplexed cupric ions the solutions were made $10^{-3}$ molal in $p$-toluenesulphonic acid in order to suppress hydrolysis. The small reduction of solvated cupric ions to cuprous ion by the amalgam is somewhat more pronounced in alcohols ${ }^{10}$ than in water, ${ }^{11}$ but is completely negligible at the low temperatures in question. It must therefore be due to other reasons that cells of this type could only be measured within a few millivolts.

For the cuprous cyanide solutions, large negative potentials of approximately one volt relative to our calomel electrode were obtained. These remained steady within some millivolts for 5 to 20 min after measurements were commenced, tending to rise to more positive potentials. This drift may be due to secondary effects, and we have assumed that the most negative potentials obtained represented the equilibrium potential.

\section{RESULTS AND DISCUSSION}

Originally it was the authors' intention to determine all the consecutive formation constants of the tetracyanocuprate(II) ion. However, owing to the difficulty in measuring the cuprous cyanide/amalgam potentials with a sufficiently high degree of accuracy, we concentrated on determining only the overall stability constant $\beta_{4}$ at a single temperature. The temperature was chosen as $-45^{\circ}$, and all experiments were made in solutions with cyanide concentrations in the range $0.05-0.1 \mathrm{~m}$. For such high cyanide concentrations at the low temperatures in question we can completely neglect hydrolysis of the cyanide, ${ }^{12}$ and it can be assumed that both the $\mathrm{Cu}(\mathrm{II})$ and the $\mathrm{Cu}(\mathrm{I})$ com-

Acta Chem. Scand. 19 (1965) No. 3 
plexes ${ }^{13}$ are present as tetracyanocuprate ions. Further it can be estimated ${ }^{14}$ that the methanol solvent has a high dielectric constant comparable to that of water at room temperature, and therefore must be a good ionizing solvent.

In some preliminary rate experiments the redox potential of a $\mathrm{Pt}$ electrode in an initially $\sim 10^{-3} \mathrm{~m}$ cupric cyanide solution $(\sim 0.05 \mathrm{~m}$ in $\mathrm{NaCN})$ was followed in time at $-20^{\circ}$. From these experiments it was concluded that the redox reaction according to eqn. (1) is second order in the concentration of the copper(II) complex. The theory is as follows. Introducing $\left[\mathrm{Cu}(\mathrm{CN})_{4}{ }^{2-}\right]=[\mathrm{Cu}(\mathrm{II})],\left[\mathrm{Cu}(\mathrm{CN})_{4}{ }^{3-}\right]=[\mathrm{Cu}(\mathrm{I})]$, we have:

$$
-\frac{\mathrm{d}[\mathrm{Cu}(\mathrm{II})]}{\mathrm{d} t}=\frac{\mathrm{d}[\mathrm{Cu}(\mathrm{I})}{\mathrm{d} t}=k_{n}[\mathrm{Cu}(\mathrm{II})]^{n}
$$

where $n$ is the order of the reaction, and $k_{n}$ the rate constant. From these expressions when $[\mathrm{Cu}(\mathrm{II})]+[\mathrm{Cu}(\mathrm{I})]=C_{\mathrm{Cu}}$ :

Now, introducing

$$
\frac{\mathrm{d} \ln ([\mathrm{Cu}(\mathrm{II})] /[\mathrm{Cu}(\mathrm{I})])}{\mathrm{d} t}=-k_{n} C_{\mathrm{Cu}} \frac{[\mathrm{Cu}(\mathrm{II})]^{n-1}}{[\mathrm{Cu}(\mathrm{I})]}
$$

$$
E={ }^{\circ} E_{\mathrm{Cu}(\mathrm{II}), \mathrm{Cu}(\mathrm{I})}+\frac{R T}{F} \ln \frac{[\mathrm{Cu}(\mathrm{II})]}{[\mathrm{Cu}(\mathrm{I})]}
$$

and differentiating, the equation

$$
\frac{\mathrm{d} E}{\mathrm{~d} t}=-\frac{R T}{F} k_{n} C_{\mathrm{cu}} \frac{[\mathrm{Cu}(\mathrm{II})]^{n-1}}{[\mathrm{Cu}(\mathrm{I})]}
$$

is obtained. In the special case where $n=2$, this can be written:

where

$$
\ln (-\mathrm{d} E / \mathrm{d} t)=A+(F / R T) E
$$

$$
A=\ln \left[(R T / F) k_{2} C_{\mathrm{Cu}}\right]-(F / R T){ }^{\circ} E_{\mathrm{Cu}(\mathrm{II}), \mathrm{Cu}(\mathrm{I})}
$$

is a constant.

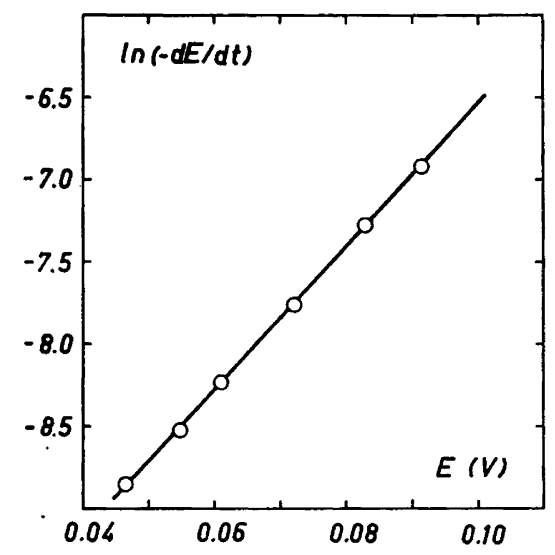

Fig. 1. Plot of rate experiment at $-20^{\circ}$ : In $(-\mathrm{d} E / \mathrm{d} t)$ versus $E$. Observed slope $=43.6$, theoretical value $F / R T=45.8$. $\ln (-\mathrm{d} E / \mathrm{d} t)$ is derived from measurements of the change of the redox potential $E$ of a $\mathrm{Cu}(\mathrm{II}), \mathrm{Cu}(\mathrm{I})$-cyanide solution with time. $[\mathrm{Cu}(\mathrm{II})]_{t=0}=1.03 \times 10^{-3}$ $\mathrm{m}, C_{\mathrm{NaCN}}=0.052 \mathrm{~m}, C_{\mathrm{NaT}}=0.048 \mathrm{~m}$. The times in minutes which correspond to the redox potentials of the points in the figure are the following: $t$ (min), $E ; 10$, $0.0914 ; 20,0.0828 ; 40,0.0721 ; 72.5,0.0610$; $100,0.0548 ; 150,0.0465$.

Acta Chem. Scand. 19 (1965) No. 3 
Table 1. Determinations of the normal potentials copper(II)/copper, tetracyanocuprate(I)/ copper, and tetracyanocuprate(II)/tetracyanocuprate(I) relative to a $(0.02 \mathrm{~m} \mathrm{NaCl}+0.08$ $\mathrm{m} \mathrm{NaT}$ )-calomel electrode in an aqueous $60 \mathrm{wt} \%$ methanol solvent at $-45^{\circ}$.

For solutions 1-3: $C_{\mathrm{HT}}=0.001 \mathrm{~m}, C_{\mathrm{NaT}}=0.1 \mathrm{~m}\left(\mathrm{~T}=p \cdot \mathrm{CH}_{3} \mathrm{C}_{6} \mathrm{H}_{4} \mathrm{SO}_{3}\right)$.

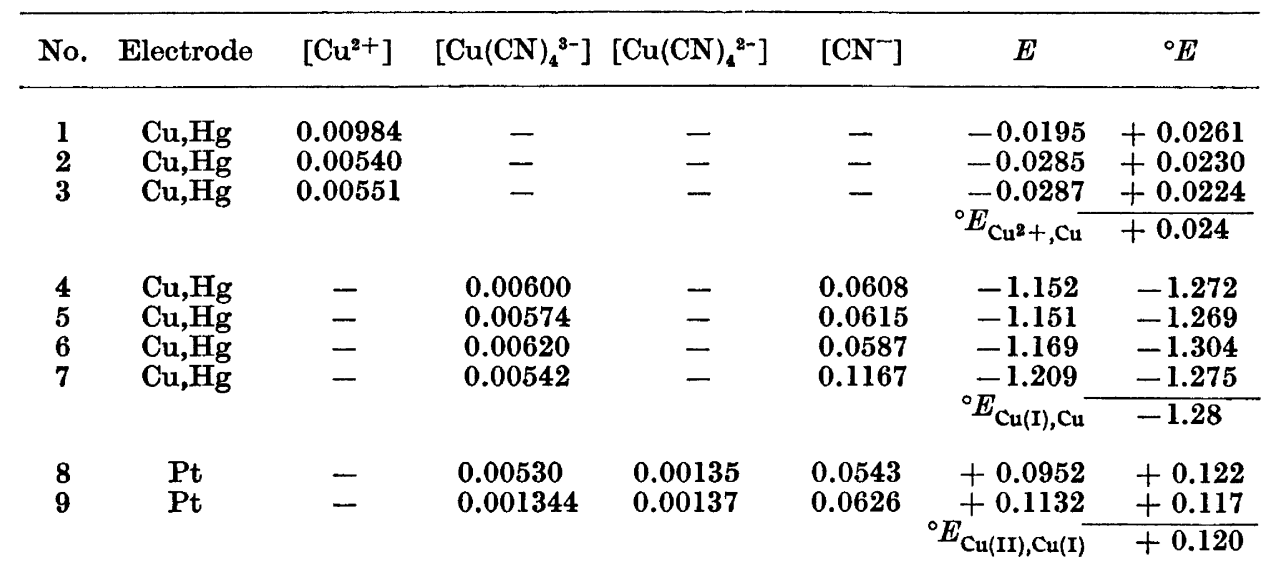

Table 2. Average complexity constant per ligand (converted to mole fraction scale) for some ammonia and cyanide systems.

\begin{tabular}{lcrrr}
\hline \multicolumn{3}{c}{$1 / N \log \beta_{\mathrm{N}}+\log 55$} \\
& $N$ & $\mathrm{NH}_{3}$ & $\mathrm{CN}^{-}$ & Ratio \\
\hline & 1 & 10.9 & 11.1 & 1.0 \\
$\mathrm{H}^{+}$ & 2 & 7.2 & 13.7 & 1.9 \\
$\mathrm{Cu}^{+}$ & 2 & 5.3 & 11.7 & 2.2 \\
$\mathrm{Ag}^{+}$ & 2 & 10.5 & 19.0 & 1.8 \\
$\mathrm{Hg}^{2+}$ & 4 & 4.1 & 6.0 & 1.5 \\
$\mathrm{Zn}^{2+}$ & 4 & $\mathbf{3 . 6}$ & 5.8 & 1.6 \\
$\mathrm{Cd}^{2+}$ & 4 & 5.0 & $\sim 8$ & 1.6 \\
$\mathrm{Cu}^{2+}$ & 6 & 7.6 & 12.4 & \\
$\mathrm{Co}^{3+}$ & & & &
\end{tabular}

In Fig. $1 \ln (-\mathrm{d} E / \mathrm{d} t)$ is plotted against $E$ for a typical experiment. It will be seen that this plot gives a straight line, and that the slope of this line agrees well with the theoretical value. This confirms that the redox reaction is second order in the $\mathrm{Cu}$ (II) concentration in agreement with the results of Baxendale and Westcott. ${ }^{2}$

The e.m.f. equilibrium measurements were, as previously mentioned, made at $-45^{\circ}$, and in $\sim 0.05-0.10 \mathrm{~m} \mathrm{NaCN}$ solutions. One mole cyanide ion per $\mathrm{Cu}$-atom is removed as $(\mathrm{CN})_{2}$ when cuprous cyanide solutions are prepared from copper(II) and cyanide. The formal concentration of free cyanide was therefore calculated as

$$
\left[\mathrm{CN}^{-}\right]=C_{\mathrm{NaCN}-}-4\left[\mathrm{Cu}(\mathrm{CN})_{4}{ }^{2-}\right]-5\left[\mathrm{Cu}(\mathrm{CN})_{4}{ }^{3-}\right]
$$


The following formal normal potentials were determined relative to the $0.02 \mathrm{~m} \mathrm{NaCl}$-calomel electrode which was used as reference electrode. With $\mathrm{Cu}, \mathrm{Hg}$-electrode:

$$
\begin{gathered}
{ }^{\circ} E_{\mathrm{Cu}^{2}+, \mathrm{Cu}}=E-0.0226 \log \left[\mathrm{Cu}^{2+}\right] \\
{ }^{\circ} E_{\mathrm{Cu}(\mathrm{I}), \mathrm{Cu}}=E-0.0453 \log \left(\left[\mathrm{Cu}(\mathrm{CN})_{4}{ }^{3-}\right] /\left[\mathrm{CN}^{-}\right]^{4}\right)
\end{gathered}
$$

and with Pt-electrode:

$$
{ }^{\circ} E_{\mathrm{Cu}(\mathrm{II}), \mathrm{Cu}(\mathrm{I})}=E-0.0453 \log \left(\left[\mathrm{Cu}(\mathrm{CN})_{4}{ }^{2-}\right] /\left[\mathrm{Cu}(\mathrm{CN})_{4}{ }^{3-}\right]\right)
$$

The data are given in Table 1. Combination of the normal potentials obtained

$$
2^{\circ} E_{\mathrm{Cu} 2+, \mathrm{Cu}}-{ }^{\circ} E_{\mathrm{Cu}(\mathrm{I}), \mathrm{Cu}}-{ }^{\circ} E_{\mathrm{Cu}(\mathrm{II}), \mathrm{Cu}(\mathrm{I})}=0.0453 \log \beta_{4}
$$

results in the value $10^{26.7}$ for $\beta_{4}\left(=K_{1} K_{2} K_{3} K_{4}\right)$. This value is in fair agreement with that predicted by one of the authors ${ }^{15}$ many years ago.

Table 2 gives the average complexity constant per ligand (converted to mole fraction scale) for some ammonia and cyanide systems at room temperature. ${ }^{16}$ It will be seen that the affinity to $\mathrm{CN}^{-}$always is higher than that to $\mathrm{NH}_{3}$, and except for the hydrogen ion, the ratio of the affinities (given in the last column) does not vary much. The value predicted for the copper(II) cyanide system ${ }^{15}$

$$
1 / 4 \log \beta_{4}+\log 55 \sim 8
$$

corresponds in the molarity (or molality) scale to $\beta_{4} \sim 10^{25}$.

Acknowledgement. The authors are grateful to Rask-Ørsted Fondet for financial support to one of us (R.P.).

\section{REFERENCES}

1. Duke, F. R. and Courtney, W. G. J. Phys. Chem. 56 (1952) 19.

2. Baxendale, J. H. and Westcott, D. T. J. Chem. Soc. 19592347.

3. Griffith, W. P. Quart. Rev. (London) 16 (1962) 188.

4. Cohen, E., Chattaway, F. D. and Tombrock, W. Z. physik. Chem. 60 (1907) 715.

5. Meyer, F. R. and Ronge, G. Z. Z. angew. Chem. 52 (1939) 637.

6. Schwarzenbach, G. Die komplexometrische Titration. Die chemische Analyse, Vol. 45, p. 77, Ferdinand Enke Verlag, Stuttgart 1961.

7. Vogel, A. I. A Text-book of Quantitative Analysis, 3rd Ed., Longmans, Green and Co., London 1961, p. 271.

8. Hills, G. J. and Ives, D. J. G. J. Chem. Soc. 1951311.

9. Gjaldbæk, J. K. Kgl. Danske Videnskab. Selskab, Mat.-Fys. Medd. 5 (1924) No. 9.

10. Nelson, I. V. and Iwamoto, R. T. Inorg. Chem. 1 (1962) 151.

11. Heinerth, E. Z. Elektrochem. 37 (1931) 61.

12. Izatt, R. M., Christensen, J. J., Pack, R. T. and Bench, A. Inorg. Chem. 1 (1962) 828.

13. Penneman, R. A. and Jones, L. H. J. Chem. Phys. 24 (1956) 293.

14. Parsons, R. Handbook of Electrochemical Constants, Butterworths Scientific Publications (1959).

15. Bjerrum, J. Chem. Rev. 46 (1950) 393.

16. Stability Constants of Metal-ion Complexes, The Chemical Society, Special Publication No. 17 (1964).

Received January 6, 1965.

Acta Chem. Scand. 19 (1965) No. 3 